\title{
IMPLEMENTATION OF POWER-EFFICIENT CONTROL UNIT ON ULTRA-SCALE FPGA FOR GREEN COMMUNICATION
}

Bishwajeet Pandey

Centre of Energy Excellence, Gyancity Research Labs.

Motihari, (India).

E-mail: gyancity@gyancity.com ORCID: https:// orcid.org/0000-0001-9674-3586

Keshav Kumar

Centre of Energy Excellence, Gyancity Research Labs.

Motihari, (India).

E-mail: keshav@gyancity.com ORCID: https://orcid.org/0000-0002-2310-5468

Aiza Batool

Sapienza University of Rome.

Rome, (Italy).

E-mail: aizabatooll@gmail.com ORCID: https:// orcid.org/0000-0001-5650-3609

Shabeer Ahmad

Gran Sasso Science Institute.

L'aquila, (Italy).

E-mail: shabeer.ahmad@gssi.it ORCID: https://orcid.org/0000-0002-2951-2259

\section{Citación sugerida:}

Pandey, B., Kumar, K., Batool, A., y Ahmad, S. (2021). Implementation of power-efficient control unit on ultrascale FPGA for green communication. 3C Tecnología. Glosas de innovación aplicadas a la pyme, 10(1), 93-105. https://doi. org/10.17993/3ctecno/2021.v10n1e37.93-105 


\section{ABSTRACT}

Whole world is suffering from the problem of the energy crisis. This is happening because of the enormous growth of population and industries across the globe. Therefore the whole world is looking to adopt the concepts of green communication technologies and power/energy efficient devices. This work is just towards these technologies. In this work, a power-efficient Control Unit (CU) is designed and implemented on Kintex-7 Ultrascale FPGA. The simulation and power analysis of the control unit is done on VIVADO HLx Design Suite. The power analysis of control unit is observed for different frequency values and it is observed that as the frequency increases the total power consumption also increases. Hence the control unit is more suitable to operate at low frequency values in order to minimize the power consumption. Also, there is a $36 \%$ saving in total power consumption when we scale down the device operating frequency of the control unit from $5 \mathrm{GHz}$ to $100 \mathrm{MHz}$.

\section{KEYWORDS}

FPGA, Control Unit, Green Communication, Power Analysis, VIVADO. 


\section{INTRODUCTION}

The rapid extent of the population and the evolution of industrialization across the globe have led to several problems for the shortage of the Earth's natural resources (Mahapatra et al., 2015; Pietrosemoli \& Rodríguez-Monroy, 2019). Therefore people are getting more concerned about saving these resources for the future generation. This can be accomplished using green communication technologies and energy/ power-efficient devices (Kumar, Pandey, \& Mohamed, 2019a; Kumar et al., 2019b).

This work is a step towards the idea to promote the technologies of green communication and energy/ power-efficient devices. In this work, a Control Unit $(\mathrm{CU})$ is implemented on FPGA to minimize the power consumption. With the help of various Low Voltage CMOS (LVCMOS) technology, Input/ output (I/O) standards researchers have designed a power-efficient CU on Artix-7 FPGA (Kumar, Pandey, \& Hussain, 2019c).

I/O standards are used to minimize power consumption by matching the input and output impedance. A power-efficient $\mathrm{CU}$ is designed by authors on Artix-7 FPGA by changing its frequency values. With the change in frequency values the power consumption of the CU with FPGA device changes (Kumar et al., 2019d). Stub Series Terminated Logic (SSTL) I/O Standards are used by researchers to improve the power consumption of CU on $40 \mathrm{~nm}$ Virtex-6 FPGA. SSTL I/O standards match the impedance of input load w.r.t to the output load, so that power consumption gets reduced (Chaturvedi, Kaushik, \& Baggan, 2019).

An electronic CU is designed by authors on FPGA for controlling the vehicles' system. The Reduced Instruction Set Computer (RISC) Machine (ARM) processor is used along with FPGA for computing parallel tasks (Pérez et al., 2019). To promote the ideas of green communication researchers have implemented a power-efficient CU on Virtex and Spartan family's FPGA (Pandey, 2020). An energyefficient $\mathrm{CU}$ is designed by authors with the help of HSTL and HSUL I/O standard for green communication on 28nm Artix-7 FPGA devices (Kumar, Pandey, \& Chaturvedi, 2019e). An energy- 
efficient instruction register is designed by authors for integrating the green communication on Virtex 4, Virtex 5, and Virtex 6 FPGA (Siddiquee et al., 2019). Therefore it has been observed that a lot of work has been done for incorporating the ideas of green communication and energy/power-efficient devices for future generation on $\mathrm{CU}$ with various FPGAs, but there is no such work is done on implementing the CU circuit on Kintex-7 ultrascale FPGA, hence in this work, the CU circuit is being designed on Kintex-7 ultrascale FPGA for promoting the techniques of green communication.

\section{METHODOLOGY}

The implementation setup for $\mathrm{CU}$ is done on the Ultra scale Kintex-7 FPGA board. The platform used for simulation of GU on the FPGA board is the VIVADO HLx design suite (Kumar et al., 2019f). For implementing CU on Ultra scale Kintex-7 FPGA board, the FPGA resources utilized are such as Lookup Tables (LUTs), Flip-flops (FF), Input-Output (IO), and Global Buffers (BUFGs) which are shown in Table 1 and Figure 1.

Table 1. FPGA resource utilization for implementing CU.

\begin{tabular}{|c|c|c|c|}
\hline RESOURCE & UTILIZATION & AVAILABLE & UTILIZATION \% \\
\hline LUT & 14 & 203128 & 0.01 \\
\hline FF & 4 & 406256 & 0.01 \\
\hline IO & 23 & 312 & 7.37 \\
\hline BUFG & 1 & 480 & 0.21 \\
\hline
\end{tabular}

Source: own elaboration.

The utilization of LUTs are 14 whereas 203128 LUTs are available on FPGA boards for designing CU. Similarly, the utilization FF, IO, and BUFG are 4, 23, and 1 respectively for designing CU on the ultrascale Kintex-7 FPGA. 


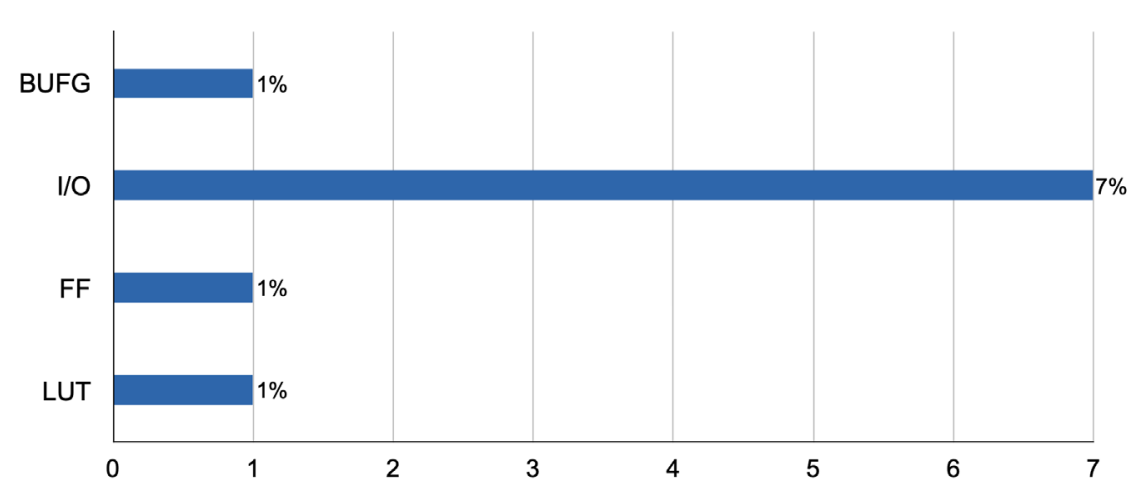

Figure 1. FPGA resource utilization for implementing CU.

Source: own elaboration.

The power analysis of $\mathrm{CU}$ for making it energy/power-efficient is done for various frequency values such as $100 \mathrm{MHz}, 500 \mathrm{MHz}, 1 \mathrm{GHz}, 3 \mathrm{GHz}$, and $\mathrm{GHz}$ which is shown in Figure 2.

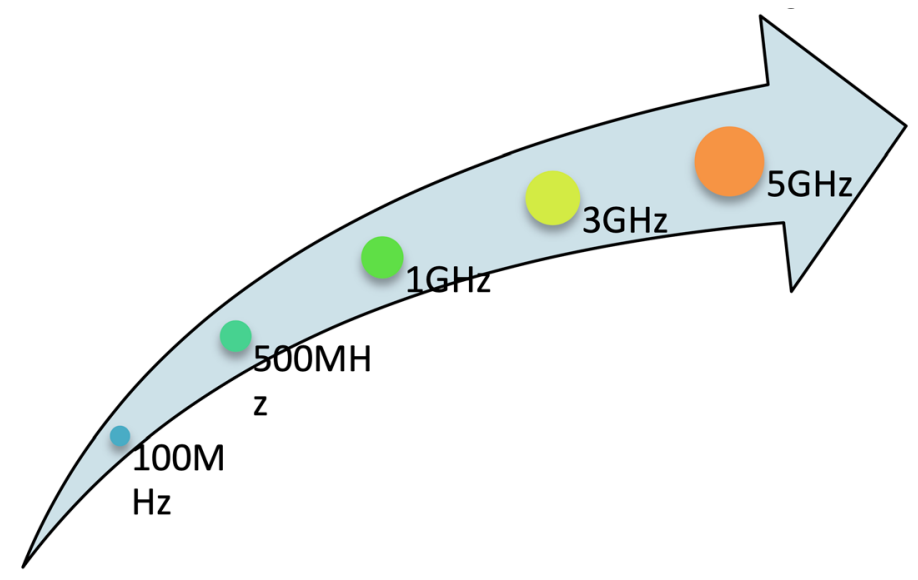

Figure 2. Frequency Values for Power Analysis.

Source: own elaboration. 


\section{RESULTS}

The power calculation of $\mathrm{CU}$ with the ultrascale Kintex-7 FPGA is associated with FPGA device Dynamic Power (DP) and Static Power (SP) (Pandey, 2019). The total power consumption is the sum of both dynamic and static power. The dynamic power is the leakage power dissipation of the device. The static power is the summation of device I/O, Logic (L/G), Signal (S/G), and Clock (Ck) power.

\section{Total Power $(T P)=D P+S P$}

\subsection{POWER ANALYSIS OF $100 \mathrm{MHZ}$ FREQUENCY}

When the frequency of $\mathrm{CU}$ is set to $100 \mathrm{MHz}$ then the power consumption is $99 \%$ for SP that is 0.457 $\mathrm{W}$ and DP consumption is $1 \%$ that is $0.007 \mathrm{~W}$. Therefore the device TP consumption is $0.464 \mathrm{~W}$. The $\mathrm{TP}$ at $100 \mathrm{MHz}$ is represented in Figure 3.

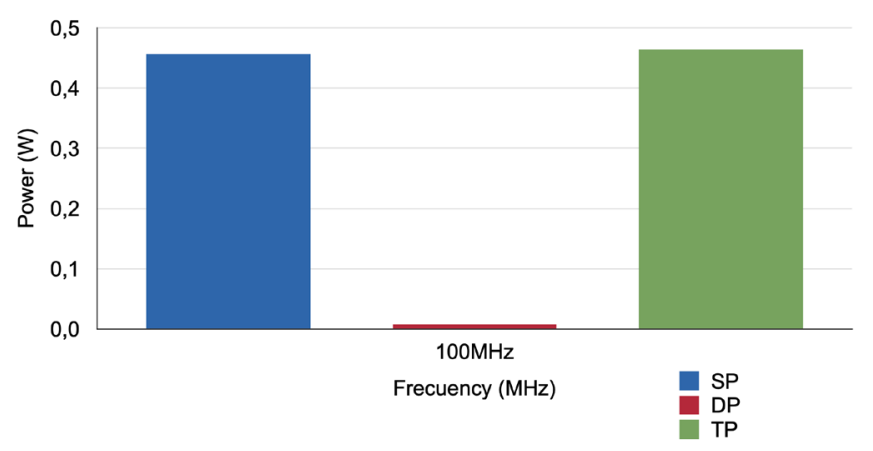

Figure 3. Power Consumption for $100 \mathrm{MHz}$.

Source: own elaboration.

\subsection{POWER ANALYSIS OF $500 \mathrm{MHZ} F R E Q U E N C Y$}

When the frequency is tuned to $500 \mathrm{MHz}$, the total power consumption of CU on the FPGA board is $0.485 \mathrm{~W}$. The TP consumption is the summation of device SP and DP. For the frequency of $500 \mathrm{MHz}$, 
the SP consumption is $0.457 \mathrm{~W}$ whereas DP consumption is $0.028 \mathrm{~W}$. The power consumption for the frequency of $500 \mathrm{MHz}$ is described in Figure 4.

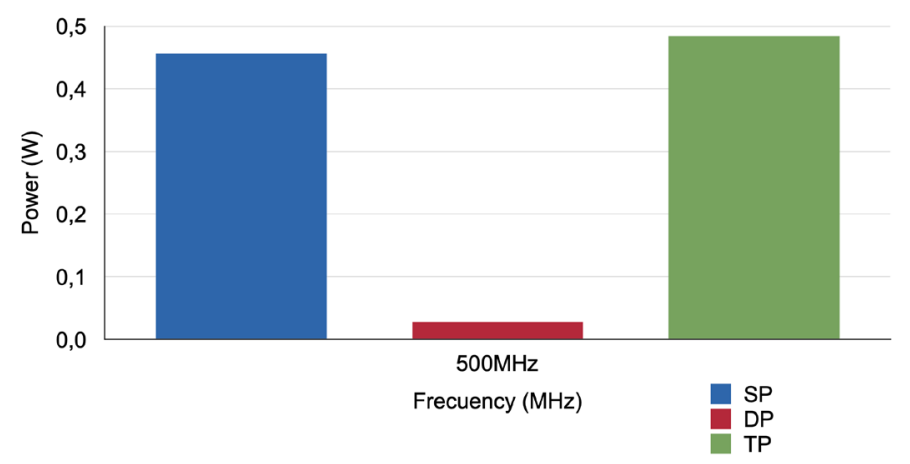

Figure 4. Power Consumption for $500 \mathrm{MHz}$.

Source: own elaboration.

\subsection{POWER ANALYSIS OF $1 \mathrm{GHZ}$ FREQUENCY}

When the frequency of $\mathrm{CU}$ is tuned to $1 \mathrm{GHz}$ then the power consumption is $89 \%$ for $\mathrm{SP}$ that is $0.457 \mathrm{~W}$ and DP consumption is $11 \%$ that is $0.054 \mathrm{~W}$. Therefore the device TP consumption is $0.512 \mathrm{~W}$. The TP at $100 \mathrm{MHz}$ is represented in Figure 5.

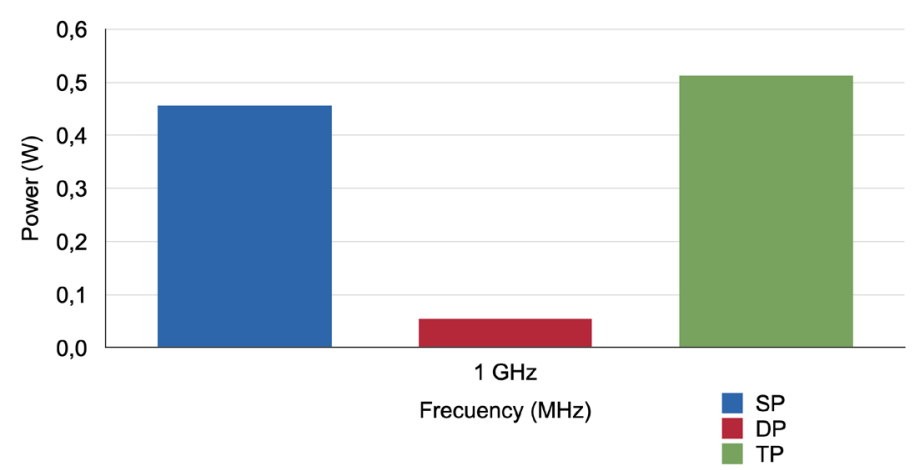

Figure 5. Power Consumption for $1 \mathrm{GHz}$.

Source: own elaboration. 


\subsection{POWER ANALYSIS OF 3 GHZ FREQUENCY}

When the frequency is tuned to $3 \mathrm{GHz}$, the total power consumption of CU on the FPGA board is $0.618 \mathrm{~W}$. The TP consumption is the summation of device SP and DP. For the frequency of $3 \mathrm{GHz}$, the SP consumption is $0.458 \mathrm{~W}$ whereas $\mathrm{DP}$ consumption is $0.160 \mathrm{~W}$. The power consumption for the frequency of $3 \mathrm{GHz}$ is described in Figure 6.

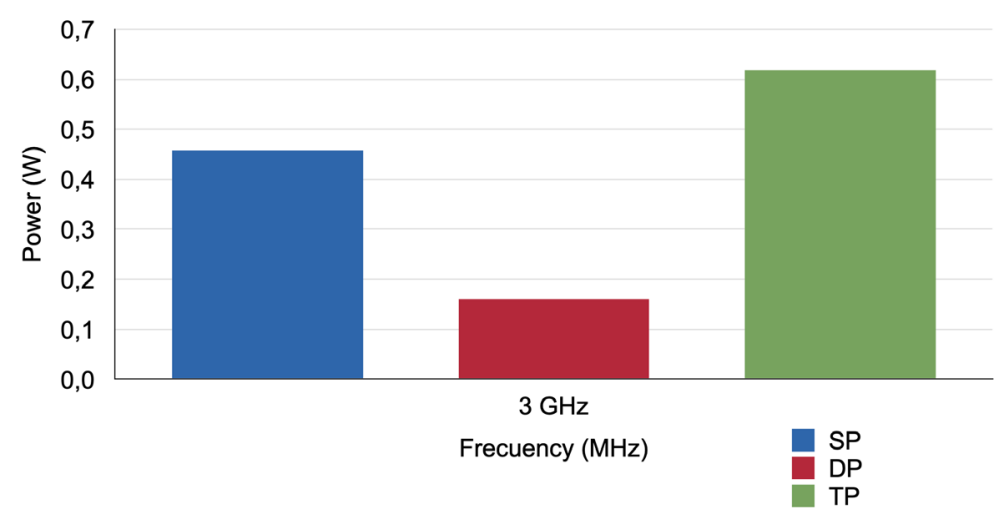

Figure 6. Power Consumption for $3 \mathrm{GHz}$.

Source: own elaboration.

\subsection{POWER ANALYSIS OF 5 GHZ FREQUENCY}

When the frequency is tuned to $5 \mathrm{GHz}$, the total power consumption of CU on the FPGA board is $0.725 \mathrm{~W}$. The TP consumption is the summation of device SP and DP. For the frequency of $5 \mathrm{GHz}$, the $\mathrm{SP}$ consumption is $0.459 \mathrm{~W}$ whereas $\mathrm{DP}$ consumption is $0.266 \mathrm{~W}$. The power consumption for the frequency of $5 \mathrm{GHz}$ is described in Figure 7. 


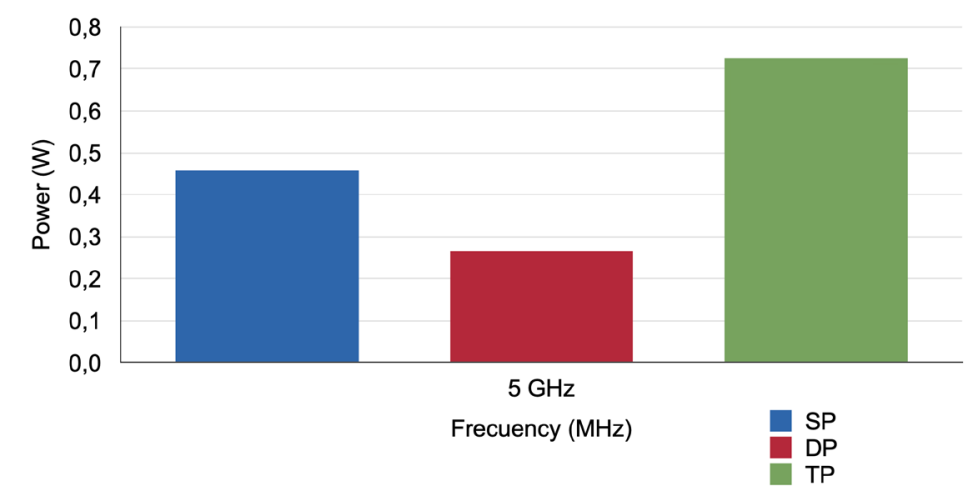

Figure 7. Power Consumption for $5 \mathrm{GHz}$.

Source: own elaboration.

\section{OBSERVATIONS AND DISCUSSION}

From the power analysis (section), it is being observed that as the frequency of operation of FPGA devices gets increased there is decrement in the SP of device for $\mathrm{GU}$ implementation and there is an increment if device DP for CU implementation. Therefore the TP gets increased, when the frequency gets increased.

The TP consumption is found minimum for $100 \mathrm{MHz}$ frequency whereas the TP consumption is found maximum for $5 \mathrm{GHz}$ frequency. There is an increment of $4.52 \%$ in TP consumption, when the frequency value is tuned to $500 \mathrm{MHz}$ from $100 \mathrm{MHz}$. Also, there is an increment of $10.34 \%, 33.18 \%$, and $56.25 \%$ in TP consumption, when the frequency value is tuned to $1 \mathrm{GHz}, 3 \mathrm{GHz}$, and $5 \mathrm{GHz}$ from $100 \mathrm{MHz}$. The total power of the control unit on an FPGA device for all frequency values are shown in Figure 8. 


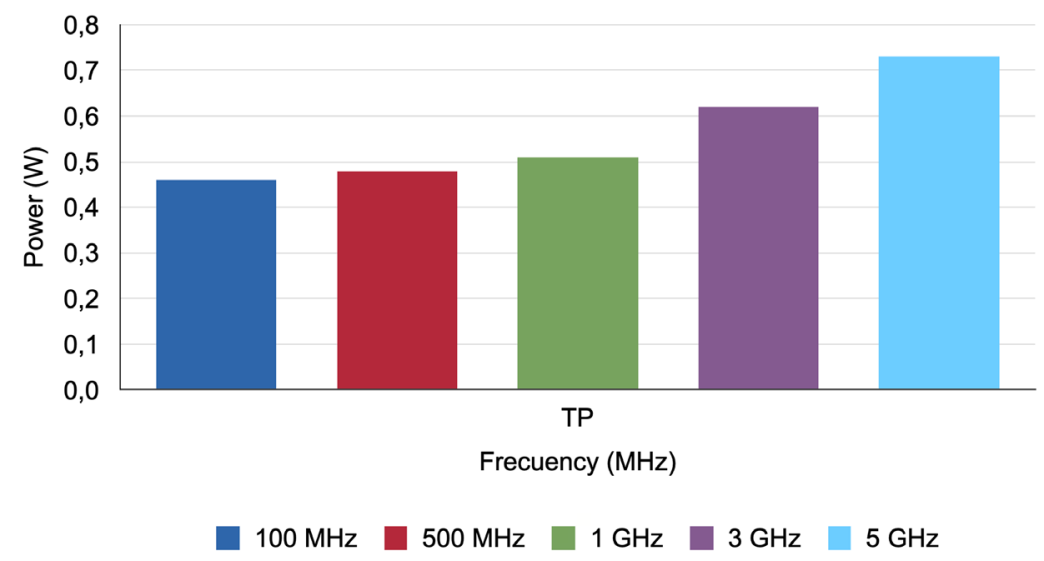

Figure 8. Total Power Consumption of CU on FPGA device.

Source: own elaboration.

\section{CONCLUSION AND FUTURE SCOPE}

The step towards green communication is very important in this era, because energy crisis is seen everywhere across the globe. Therefore from this research work, it has been tried to make some steps towards promoting the principles of green communication and power-efficient devices. In this work, the implementation of $\mathrm{CU}$ is done on Kintex-7 ultrascale FPGA, and the simulation of $\mathrm{CU}$ circuit, resources utilization, and power analysis is observed on VIVADO Hlx Design Suite.

The power consumption of CU on FPGA devices is analyzed for five different sets of frequency values such as $100 \mathrm{MHz}, 500 \mathrm{MHz}, 1 \mathrm{GHz}, 3 \mathrm{GHz}$, and $5 \mathrm{GHz}$. It is observed that the power consumption increases as the value of frequency increases. Therefore it can be concluded that lower the frequency value lower the total power consumption. The CU circuit consumes the least amount of power for 100 $\mathrm{MHz}$ frequency. 
As future scope is concerned, this GU circuit can be analyzed for other ultra-scale and ultrascale plus FPGA devices. Not only this other power-efficient techniques such as voltage, current, and capacitance scaling techniques can be applied to the $\mathrm{CU}$ circuit. Impedance matching techniques with the help of I/O standards can also be applied to make circuit energy-efficient. Later this FPGA design can be converted to ASIC designs for better performance.

\section{REFERENCES}

Ghaturvedi, S. P., Kaushik, A., \& Baggan, V. (2019). Power Efficient Control Unit Design Using 40nm Field Programmable Gate Array. International Fournal of Advanced Science and Technology, (19), 694 - 709. http://sersc.org/journals/index.php/IJAST/article/view/2654

Kumar, K., Pandey, P., \& Mohamed, R. R. (2019a). HSTL and HSUL I/O Standard Based EnergyEfficient Control Unit Circuit Design on FPGA. http://gjecs.gyancity.com/Vol4No2/GJECS_42003. pdf

Kumar, K., Ahmad, S., Pandey, B., Pandit, A. K., Singh, D., \& Akbar, D. M. (2019b). Power Efficient Frequency Scaled and ThermalAware Control Unit Design on FPGA. International fournal of Innovative Technology and Exploring Engineering (IfITEE), 8(9 Special Issue 2), 530-533.

Kumar, K., Pandey, B., \& Hussain, D. A. (2019c). Power Efficient UART Design Using Capacitive Load on Different Nanometer Technology FPGA. Gyancity fournal of Engineering and Technology, 5(2).

Kumar, K., Pandey, B., \& Hussain, D. M. A. (2019d). Effect of Frequency on Energy Efficient Transceiver Design. Gyancity Journal of Engineering and Technology, 5(2), 14-18. https://doi. $\mathrm{org} / 10.21058 /$ gjet.2019.52002

Kumar, K., Pandey, B., \& Chaturvedi, S. P. (2019e). Frequency Scaled Green Data Flip Flop on Different Nanometer Technology Based FPGA. Gyancity Fournal of Electronics and Computer Science, $4(1), 1-7$. 
Kumar, K., Pandey, B., Hussian, D. M. A., Bhutto, A., Pandit, A. K., \& El-Ebiary, Y. A. B. (2019f). Design of Energy Efficient Control Unit and Implementation on High Performance FPGA. International Journal of Innovative Technology and Exploring Engineering (IFITEE), 8(12S2).

Mahapatra, R., Nijsure, Y., Kaddoum, G., Hassan, N. U., \& Yuen, G. (2015). Energy efficiency tradeoff mechanism towards wireless green communication: A survey. IEEE Communications Surveys E Tutorials, 18(1), 686-705.

Pandey, B., Kumar, K., Haryanti, S. G., Mohamed, R. R., \& Hussian, D. A. (2020). Power Efficient Control Unit for Green Communication.

Pandey, B., Pandey, N., Kaur, A., Hussain, D. A., Das, B., \& Tomar, G. S. (2019). Scaling of output load in energy efficient FIR filter for green communication on ultra-scale FPGA. Wireless Personal Communications, 106(4), 1813-1826. https://link.springer.com/article/10.1007/s11277018-5717-2

Pérez, J., Alcázar, M., Velasco, J. M., Cabrera, J. A., \& Castillo, J. J. (2019). Low-Cost FPGABased Electronic Control Unit for Vehicle Control Systems. Sensors, 19(8), 1834. https://doi. org/10.3390/s19081834

Pietrosemoli, L., \& Rodríguez-Monroy, G. (2019). The Venezuelan energy crisis: Renewable energies in the transition towards sustainability. Renewable and Sustainable Energy Reviews, 105, 415426. https://ideas.repec.org/a/eee/rensus/v105y2019icp415-426.html

Siddiquee, M. T., Kumar, K., Pandey, P., \& Kumar, A. (2019). Energy Efficient Instruction Register for Green Communication. International Fournal of Engineering and Advanced Technology (IfEAT), o(2S2). https://www.ijeat.org/wp-content/uploads/papers/v8i2s2/B10650182S219.pdf 
